ПЕДАГОГИКА

DOI: $10.17805 /$ trudy.2018.4.1

\title{
ПЕДАГОГИЧЕСКИЙ МЕНЕДЖМЕНТ НА ОСНОВЕ ПРИНЦИПА НЕНАСИЛИЯ*
}

\author{
B. A. Сuтаров \\ Московский гуманитарный университет
}

\begin{abstract}
Аннотация: Статья посвящена теоретическому анализу педагогического менеджмента на основе принципа ненасилия. Дается сравнительная характеристика педагогического менеджмента, построенного на принципе принуждения, $и$ педагогического менеджмента, построенного на принципе ненасилия.
\end{abstract}

Ключевые слова: педагогический менеджмент, педагогика ненасилия; принцип принуждения; принцип ненасилия; ненасильственные компетенции; магистерская программа; «Менеджмент в образовании»

\section{PEDAGOGICAL MANAGEMENT BASED ON THE NON-COERCION PRINCIPLE}

\author{
V. A. Sitarov \\ Moscow University for the Humanities
}

\begin{abstract}
The paper is dedicated to a theoretical analysis of pedagogical management based on the principle of non-coercion. The author gives a comparative characteristic of pedagogical management built on the principle of coercion, and pedagogical management built on the principle on non-coercion.
\end{abstract}

Keywords: pedagogical management; pedagogy of non-coercion; principle of coercion; principle of non-coercion; non-coercive competencies; master's course; "Management in Education"

\section{Введение}

Педагогический менеджмент - это относительно новое понятие в современной отечественной педагогической науке и практике. Оно возникло в конце XX века в период социально-экономических преобразований в нашей стране, которые коснулись также и сферы образования. В это же время воспитание граждан общества с предпринимательским типом мышления

\footnotetext{
* Исследование выполнено при финансовой поддержке РФФИ в рамках научного проекта № 18-013-00151.

The research is financially supported by the RFBR within the scientific project No. 18-01300151.
} 
становится одной из основных задач, стоящих перед «новой» российской школой. В связи с этим в этот исторический период ставится задача обновления новой терминологии и методологии. Поэтому появилось множество не переводимых, а лишь копируемых западных терминов, например, «менеджер», «маркетинг», «консалтинг» и множество других. К таким терминам относится и «педагогический менеджмент», который пришел на смену устоявшемуся термину «управление образованием».

Отношение к этому понятию неоднозначно. Некоторые исследователи отмечают, что термин «менеджмент» имеет своей «родиной» совершенно другую социальную среду со своими деловыми представлениями, задающими свою тональность. Например, с точки зрения англо-американских представлений «менеджмент образования» ставит своей целью достижение поставленных целей и задач, результаты которых очень часто находят выражение в количественных значениях. В частности, В. А. Ефремов и В.А. Москвин (Ефремов, Москвин, 2010), изучая понятие «менеджмент», констатировали следующее: «...в нашем обществе получили прописку понятия, культурологические корни которых уходят в другой, исторический, национальный и экономический контекст. А посему эти понятия воспринимаются чаще не на мысленном, а на чувственном уровне, приводит специалистов к взаимному непониманию». И далее авторы пишут: «..термин, взятый из совершенно иной социальной системы, где существует совсем другая деловая среда со своими понятиями, представлениями и обычаями делового оборота» (там же: 45).

Другие авторы пытаются найти в данном понятии новый смысл, который отличает его от понятия «управление образованием». Этот новый смысл усматривается в идее гуманизации образования. Например, Т. С. Плесовских рассматривает педагогический менеджмент в качестве альтернативы командно-административной системы управления в образовании (Плесовских, 2009). Эту же идею в своем обзоре отстаивает и Е. С. Харченко, которая ссылаясь на работы ряда отечественных исследователей (Т. И. Шамова, Ю. А. Конаржевский и др.), отмечает, что в понятии «педагогический менеджмент» нашли отражение демократические и гуманистические отношения людей друг к другу (Харченко, 2017: Электр. ресурс).

Мы считаем, что управление образованием и педагогический менеджмент имеют одинаковую организационную структуру, в основе которой лежит замкнутая последовательность основных видов управленческой деятельности. В ходе осуществления этих видов деятельности решаются хорошо всем известные задачи: формулирование цели образовательного процесса; его планирование; обоснование необходимого ресурсного обеспе- 
чения; прогнозирование возможных результатов; принятие управленческого решения, направленного на достижение цели; мотивация всех участников на успешное решение поставленных задач; осуществление контроля и координации действий всех участников; анализ полученных результатов в соответствии с поставленной целью. В специальной литературе, касающейся проблем педагогического менеджмента, эта общая модель управления лишь адаптируется к сфере образования. В частности, В. Е. Цибульникова (Цибульникова, 2009), рассмотрев несколько десятков различных определений понятия «внутришкольное управление» как наиболее референтной части понятия «педагогический менеджмент», выделила пять основных позиций трактовки дефиниции «внутришкольное управление», а именно, управление определяется как процесс, как деятельность, как система, как воздействие и как взаимодействие.

Таким образом, можно констатировать, что педагогический менеджмент — «правопреемник» понятия «управление образованием». Его введение связано с констатацией новых реалий, в которых оказалась Россия, в том числе и образование, в частности, такой его аспект, как инновационность.

Мы считаем, что педагогический менеджмент, как и менеджмент в любой другой сфере, может строиться как на принципе принуждения, так и на принципе ненасилия. Поэтому для многих исследователей оказалась очень привлекательной идея наделить педагогический менеджмент гуманистической составляющей, противопоставив его понятию «управление образованием», которое якобы несет в себе отголоски командно-административной системы. По-нашему мнению, не является принципиальным, как мы называем систему управления в образовании традиционно, или современно как «педагогический менеджмент». Действительно важным являются вопросы, на каких принципах строится эта система: на принципе принуждения (вариант манипулирование) или на принципе ненасилия (вариант невмешательство)? В чем отличие менеджмента на основе принципа принуждения и менеджмента на основе ненасилия? К сожалению, необходимо констатировать, что нередко на словах провозглашаются гуманистические принципы, в том числе и принцип ненасилия, а на деле в открытой или скрытой форме реализуются различные формы принуждения. Сказанное позволяет сделать заключение об актуальности проблемы выявления различий педагогического менеджмента, построенного на принципах принуждения или ненасилия, определения на этой основе требований и компетенций, которыми должен обладать субъект управленческой деятельности. Этой цели и посвящена настоящая статья. 
Научные труды Московского гуманитарного университета 2018 № 4

\section{Характеристика подхода}

Одним из первых исследователей в нашей стране, кто обратил внимание на принуждение и ненасилие в образовании через призму управления, был Ю. М. Орлов (Орлов, 1997). Автор выделяет две парадигмы управления в образовании, используя для этой цели модель взаимодействия учителя и ученика. Приведем формулировку этих парадигм. Парадигма насилия: если ты не совершишь действия, то будет неприятная эмоция. Иными словами, если нет действия, то тебя ждут отрицательные переживания. В данном случае, по мнению автора, предвосхищение плохого переживания является стимулятором поведения управляемого человека. Это явное насилие, принуждение, которое совершается по схеме: если ты совершишь нужное действие, то у тебя не будет неприятностей. Парадигма ненасилия: в противоположность парадигме насилия формула ненасилия имеет опору на положительную эмоцию. «Если ты совершишь нужное управителю поведение, у тебя будет хорошая эмоция». Таким образом, согласно Ю. М. Орлову, отличительным признаком управления на основе принуждения или ненасилия являются последствия совершенных или несовершенных в данном случае учеником действий. Управление, в основе которого лежит принуждение, ориентировано на актуализацию отрицательных эмоций при невыполнении задачи, поставленной управленцем. Управление же, основанное на ненасилии, наоборот, ориентировано на актуализацию положительных эмоций при выполнении задачи, поставленном управленцем.

Мы полностью разделяем такой подход, в то же время следует отметить, что он затрагивает лишь одну сторону управленческого процесса, другие составляющие этого процесса остались вне поля зрения автора. В нашей концепции мы постарались преодолеть эту односторонность. Методологической основой развиваемой нами концепции явились теоретические положения понимания ненасилия, разработанные нами совместно с В. Г. Мараловым. Приведем их в сжатом виде:

- ненасилие выступает как жизнеутверждение, состоящее в способности человека в каждый конкретный момент своей жизни выбирать из ряда альтернатив такие, которые несут в себе наименьший заряд принуждения;

- ненасилие есть особая сила, заключающаяся в уверенности, динамизме, способности к постоянному поиску такого решения, которое наносит минимальный ущерб другим;

- ненасилие - это одновременно и способность к преодолению эгоцентризма, выражению любви, что проявляется в умении отделять личность от поступков, понимать логику действий другого, принимать человека, вставать в самые различные позиции; 
- ненасилие это проявление независимости, автономность личности, что выражается в способности не идти на поводу у социального окружения, в умении осуществлять свободные выборы с возложением на себя истинной ответственности;

- ненасилие как ценность это и сам процесс взаимодействия, выражающийся в умении совершать ненасильственное действие и оказывать ненасильственное сопротивление (Маралов, Ситаров, 2015: 63-77).

Применительно к образовательному процессу эти положения были нами конкретизированы в следующих принципах педагогики ненасилия: принципе субъективной свободы для всех участников образовательного процесса; принципе создания ненасильственной развивающей социально-педагогической среды; принципе насыщения жизнедеятельности образовательных организаций ненасильственным содержанием; принципе личностного подхода ко всем участникам образовательного процесса.

Опираясь на эти теоретические положения, попытаемся показать отличие педагогического менеджмента, построенного на принципе принуждения, от педагогического менеджмента, построенного на принципе ненасилия (см. таблицу 1).

Таблица 1. Сравнительная характеристика педагогического менеджмента, построенного на принципе принуждения, от педагогического менеджмента, в основе которого лежит принцип ненасилия

\begin{tabular}{|c|c|c|}
\hline $\begin{array}{c}\text { Структурные ком- } \\
\text { поненты управле- } \\
\text { ния }\end{array}$ & Принцип принуждения & Принцип ненасилия \\
\hline Основной лозунг & $\begin{array}{l}\text { Современный } \quad \text { менед- } \\
\text { жмент - это управление } \\
\text { задачами, а не людьми }\end{array}$ & $\begin{array}{l}\text { Современный менеджмент - это не- } \\
\text { насильственное управление людьми, } \\
\text { которые способны решать задачи }\end{array}$ \\
\hline Постановка цели & $\begin{array}{l}\text { Не оценивается с пози- } \\
\text { ций безопасности. Цель } \\
\text { оправдывает средства }\end{array}$ & $\begin{array}{l}\text { Оценивается с позиций безопасно- } \\
\text { сти. Не ставятся цели, способные } \\
\text { нанести непоправимый ущерб лич- } \\
\text { ности или системе. Цель не оправды- } \\
\text { вает средства, если это наносит вред }\end{array}$ \\
\hline $\begin{array}{l}\text { Субъект управле- } \\
\text { ния }\end{array}$ & $\begin{array}{l}\text { Является одно лицо или } \\
\text { несколько лиц, занимаю- } \\
\text { щих доминирующее по- } \\
\text { ложение в образователь- } \\
\text { ной системе }\end{array}$ & $\begin{array}{l}\text { Каждый участник образовательного } \\
\text { процесса является субъектом своей } \\
\text { собственной деятельности, напри- } \\
\text { мер, учитель - субъект педагогиче- } \\
\text { ской деятельности, ученик - субъ- } \\
\text { ект учебной деятельности, и каждый } \\
\text { несет всю полноту ответственности } \\
\text { за свой участок общей деятельности }\end{array}$ \\
\hline
\end{tabular}


Научные труды Московского гуманитарного университета

2018 № 4

\begin{tabular}{|c|c|c|}
\hline $\begin{array}{l}\text { Мотивация участ- } \\
\text { ников }\end{array}$ & $\begin{array}{l}\text { Основана на запугива- } \\
\text { нии, угрозах, актуализа- } \\
\text { ции отрицательных эмо- } \\
\text { ций при невыполнении } \\
\text { задания }\end{array}$ & $\begin{array}{l}\text { Основана на прояснении смыслов } \\
\text { выполняемой деятельности, значи- } \\
\text { мости достижения цели, ориенти- } \\
\text { рована на достижение успеха, поло- } \\
\text { жительных переживаний и чувства } \\
\text { гордости за хорошо выполненное } \\
\text { задание }\end{array}$ \\
\hline Принятие решения & $\begin{array}{lr}\text { Чаще единолично при- } \\
\text { нимается } \\
\text { управления }\end{array}$ & $\begin{array}{l}\text { В процесс принятия решения вклю- } \\
\text { чаются все участники процесса. Ре- } \\
\text { ализуется принцип демократизма с } \\
\text { четким разделением полномочий }\end{array}$ \\
\hline $\begin{array}{l}\text { Противоречие меж- } \\
\text { ду целями и зада- } \\
\text { чами, которые ста- } \\
\text { вит управленец, и } \\
\text { целями и задачами } \\
\text { исполнителей }\end{array}$ & $\begin{array}{l}\text { Преодолевается путем } \\
\text { прямого принуждения } \\
\text { или манипулирования, } \\
\text { интересы исполнителей } \\
\text { не учитываются }\end{array}$ & $\begin{array}{l}\text { Преодолевается путем сотрудниче- } \\
\text { ства, максимального учета интере- } \\
\text { сов и потребностей исполнителей, } \\
\text { ненасильственного присоединения } \\
\text { управленца участников к «своим» } \\
\text { целям и задачам, либо посредством } \\
\text { присоединения к целям и задачам } \\
\text { участников образовательного про- } \\
\text { цесса с постепенной переориентаци- } \\
\text { ей их деятельности в нужное русло } \\
\text { посредством создания адекватной } \\
\text { мотивационной основы }\end{array}$ \\
\hline $\begin{array}{l}\text { Характер осущест- } \\
\text { вления деятельно- } \\
\text { сти по достижению } \\
\text { цели }\end{array}$ & $\begin{array}{l}\text { Часто носит формаль- } \\
\text { ный, стереотипный ха- } \\
\text { рактер. Важно достичь } \\
\text { цель, чтобы к тебе «не } \\
\text { приставали» и не приме- } \\
\text { няли санкций }\end{array}$ & $\begin{array}{l}\text { Носит неформальный характер. При- } \\
\text { ветствуется творчество и инициати- } \\
\text { ва, которые поощряются как управ- } \\
\text { ленцем, так и исполнителями }\end{array}$ \\
\hline Kor & $\begin{array}{l}\text { Носят жесткий характер, } \\
\text { невыполнение задания } \\
\text { чревато различными } \\
\text { санкциями }\end{array}$ & $\begin{array}{l}\text { Носят гибкий характер, ориентиро- } \\
\text { ваны на выявление конкретных при- } \\
\text { чин невыполнения задания, оказа- } \\
\text { ние в случае необходимости помощи }\end{array}$ \\
\hline Kop & $\begin{array}{l}\text { Осуществляется на осно- } \\
\text { ве получения конечного } \\
\text { результата }\end{array}$ & $\begin{array}{l}\text { Осуществляется в ходе выполнения } \\
\text { задания. Корректируется не только } \\
\text { конечный результат, но и способы } \\
\text { его достижения }\end{array}$ \\
\hline $\begin{array}{l}\text { Значимость резуль- } \\
\text { тата }\end{array}$ & $\begin{array}{l}\text { Результат значим для } \\
\text { отчета, для управленца } \\
\text { важно получить одобре- } \\
\text { ние вышестоящего руко- } \\
\text { водства }\end{array}$ & $\begin{array}{l}\text { Результат значим для коллектива, } \\
\text { для удовлетворения потребности в } \\
\text { самореализации и творчестве каж- } \\
\text { дого участника }\end{array}$ \\
\hline
\end{tabular}

Как видно из таблицы 1, педагогический менеджмент, основанный на принципе принуждения, существенно отличается от педагогического менеджмента, построенного на принципе ненасилия. Эти отличия касаются всех этапов принятия и реализации управленческого решения.

Основное отличие состоит в том, что в первом случае «исполнители» выступают в качестве объектов деятельности управленца, они устранены от 
принятия решения, хотя такая возможность и постулируется на словах. Их задача хорошо выполнить задание, достичь результата. Мотивация часто носит внешний характер и основана на запугивании и угрозах. Результат нередко носит формальный характер и важен только для отчета. В педагогическом же менеджменте, основанном на принципе ненасилия, каждый участник является полноправным субъектом деятельности, его работа поощряется и мотивируется, в результате чего он хорошо понимает смысл предстоящей деятельности, ориентирован на успех, способен переживать положительные эмоции как за свою часть работы, так и за успех других. Он способен к инициативе и творчеству, не испытывает тревожности и страха, хорошо понимает значимость выполненной работы для своего развития и для других людей.

Осуществлять педагогический менеджмент на основе принципа принуждения гораздо легче, чем на основе принципа ненасилия: «Приказал сделали, не сделали - наказание». Педагогический менеджмент, основанный на принципе ненасилия, предъявляет особые требования к личности субъекта управления, к уровню его профессиональной компетентности. Важнейшими из этих компетенций являются: способность выстраивать отношения со всеми участниками образовательного процесса на принципе ненасилия; способность организовывать их деятельность и взаимодействие на ненасильственной основе.

В первом случае акцент делается на особом типе отношения к людям, проявляющимся во взаимном уважении, эмпатии, доверии, понимании, способности к принятию «Другого», терпимости. Во втором - на организационном компоненте управления, выражающимся в способности к постановке целей и обосновании их смыслов, в максимальном учете интересов при принятии решения всех сторон взаимодействия, достижение целей на основе сотрудничества, способности к рефлексивному управлению, создание атмосферы безопасности и творчества.

Интеграция этих компетенции осуществляется в способности личности принимать позицию ненасилия. Позицию ненасилия мы определяем как систему взглядов, ценностей, установок, мотивов, где выражается стремление человека строить отношения с другими людьми, природой, миром в целом на ненасильственной основе, без открытых и скрытых форм принуждения, что достигается посредством свободного и ответственного выбора, умения совершать ненасильственные действия и оказывать ненасильственное сопротивление

Формирование указанных и позиции ненасилия как их интеграции компетенций легло в основу образовательной магистерской программы «Педагогический менеджмент», которая успешно реализуется нами в Московском гуманитарном университете с 2014 г. 
Научные труды Московского гуманитарного университета 2018 № 4

Базовым здесь является курс «Педагогика ненасилия» с психолого-педагогическим практикумом. Цель курса - ознакомление студентов с идеями ненасилия как общечеловеческой ценностью, создание предпосылок для овладения позицией ненасилия и способами ненасильственного взаимодействия. Теоретическая часть представлена в пяти модулях. Основная ее задача - создать предпосылки для усвоения студентами ненасилия как общечеловеческой ценности. Представлены следующие модули: «Философия ненасилия»; «Психология ненасилия»; «Педагогика ненасилия»; «Ненасильственное взаимодействие педагогов с учащимися»; «Реализация идей педагогики и психологии ненасилия в практику образовательных организаций».

Практико-ориентированная часть спецкурса осуществляется в групповой форме в виде выполнения практических заданий и тренингов. Ее задача - создать предпосылки для анализа собственного жизненного опыта и принятия позиции ненасилия, В организации работы со студентами нами использовались следующие технологии (Маралов, 2015: Электр. ресурс; Маралов, Ситаров, 2016):

- технологии, ориентированные на самопринятие личности;

- технологии, ориентированные на осознание психологических защит;

- технологии, ориентированные на осознание стереотипов и уровня эгоцентризма;

- технологии, ориентированные на осознание своего отношения к другим людям, приобретение терпимости;

- технологии, ориентированные на бучение конкретным навыкам ненасильственного взаимодействия с людьми и в сфере управленческой деятельности.

Опыт внедрения этого курса и психолого-педагогического практикума в течение нескольких лет со всей определенностью позволяет сделать заключение о принципиальной возможности уже в вузе формировать у магистров - будущих менеджеров в сфере образования компетенции, которые базируются на принципах педагогики и психологии ненасилия.

\section{Заключение}

Итак, в настоящей статье мы попытались показать основные различия педагогического менеджмента, построенного на принципе принуждения, от педагогического менеджмента, в основе которого лежит принцип ненасилия. Нами были выделены два вида специальных компетенций, которые находят свое интегрированное выражение в позиции ненасилия. Кратко охарактеризованы основные направления работы по формированию этих компетенций на примере реализации магистерской программы «Менед- 
жмент в образовании». Предлагаемый нами подход может быть использован в вузах в ходе реализации специальных магистерских программ, а также в процессе подготовки специалистов высшей квалификации.

\section{СПИСОК ЛИТЕРАТУРЫ}

Ефремов, В. С., Москвин, В. А. (2010) Менеджмент в России: что мы имеем и что мы хотим? // Высшее образование сегодня. № 1. С. 44-48.

Маралов, В. Г. (2015) Психологические особенности ненасильственного отношения к себе [Электронный ресурс] // Научно-методический электронный журнал «Концепт». № 5 (май). URL: http://e-koncept.ru/2015/15157.htm (дата обращения: 29.07.2018).

Маралов, В. Г., Ситаров, В. А. (2015) Педагогика и психология ненасилия в образовании. М. : Юрайт. 424 с.

Маралов, В. Г., Ситаров, В. А. (2016) Психолого-педагогические условия формирования ненасильственного отношения к другим людям (на примере студенческой молодежи) // Знание. Понимание. Умение № 2. С. 246-258.

Орлов, Ю. М. (1997) Психология принуждения. М. : Импринт-Гольфстрим. $32 \mathrm{c}$.

Плесовских, Т. С. (2009) Педагогический менеджмент как альтернатива административно-командного управления в инновационных образовательных учреждениях // Казанский педагогический журнал. № 7-8. С. 65-71.

Харченко, Е. С. (2017) Из истории возникновения понятия педагогического менеджмента в России [Электронный ресурс] // Научные труды Московского гуманитарного университета. № 4. URL: http://journals.mosgu. ru/trudy/article/view/530 (дата обращения: 29.07.2018). DOI: 10.17805/ trudy.2017.4.7

Цибульникова, В. Б. (2009) Формирование научных взглядов на категорию «внутришкольное управление» в отечественной педагогике // Вестник ТГУ. Выпуск 12(80). С. 200-205.

Дата поступления: 12.08.2018 2.

Ситаров Вячеслав Алексеевич - доктор педагогических наук, профессор, заведующий кафедрой педагогики и психологии высшей школы Московского гуманитарного университета. Адрес: 111395, Россия, г. Москва, ул. Юности, д. 5 . Тел.: +7 (495) 374-74-59. Эл. адрес: sitarov@mail.ru 
Sitarov Viacheslav Alekseevich, Doctor of Pedagogy, Professor, Chair, Department of the Pedagogy and Psychology of Higher School, Moscow University for the Humanities. Postal address: 5 Yunosti St., Moscow, Russian Federation, 111395. Tel.: +7 (495) 374-74-59. E-mail: sitarov@mail.ru

\section{Для цитирования:}

Ситаров В. А. Педагогический менеджмент на основе принципа ненасилия [Электронный ресурс] // Научные труды Московского гуманитарного университета. 2018. № 4. URL: http://journals.mosgu.ru/trudy/article/ view/805(дата обращения: дд.мм.гг.). DOI: 10.17805/trudy.2018.4.1 